\title{
The Role of Adiponectin in the Skin
}

\author{
Jieun $\mathrm{Oh}^{1, \dagger}$, Yeongyeong Lee ${ }^{1, \dagger}$, Sae-Woong $\mathrm{Oh}^{2, \dagger}$, TianTian $\mathrm{Li}^{1}$, Jiwon Shin ${ }^{1}$, See-Hyoung Park ${ }^{3, *}$ and \\ Jongsung Lee ${ }^{1,2, *}$
}

${ }^{1}$ Department of Integrative Biotechnology, College of Biotechnology and Bioengineering, Sungkyunkwan University, Suwon 16419, ${ }^{2}$ Molecular Dermatology Laboratory, Department of Integrative Biotechnology, College of Biotechnology and Bioengineering,

Sungkyunkwan University, Suwon 16419,

${ }^{3}$ Department of Bio and Chemical Engineering, Hongik University, Sejong 30016, Republic of Korea

\begin{abstract}
Adiponectin (Ad), a $30 \mathrm{kDa}$ molecule, is an anti-diabetic adipokine; although derived from adipose tissue, it performs numerous activities in various other tissues. It binds to its own receptors, namely adiponectin receptor 1(AdipoR1), adiponectin receptor 2 (AdipoR2), and T-cadherin (CDH13). Ad plays several roles, especially as a regulator. It modulates lipid and glucose metabolism and promotes insulin sensitivity. This demonstrates that Ad has a robust correlation with fat metabolism. Furthermore, although Ad is not in direct contact with other tissues, including the skin, it can be delivered to them by diffusion or secretion via the endocrine system. Recently it has been reported that Ad can impact skin cell biology, underscoring its potential as a therapeutic biomarker of skin diseases. In the present review, we have discussed the association between skin cell biology and Ad. To elaborate further, we described the involvement of Ad in the biology of various types of cells in the skin, such as keratinocytes, fibroblasts, melanocytes, and immune cells. Additionally, we postulated that Ad could be employed as a therapeutic target to maintain skin homeostasis.
\end{abstract}

Key Words: Adiponectin, Keratinocyte, Melanocyte, Fibroblast, Innate immunity, Adaptive immunity

\section{INTRODUCTION}

Twenty years ago, Ad was discovered and characterized as a fat-derived hormone. As a crosstalk molecule between adipose tissue and other metabolism-related organs, it has been widely studied (Scherer, 2006; Deng and Scherer, 2010). Ad has been the subject of considerable interest in the field of metabolism, and significant steps have been taken to analyze and unravel its mechanism of action. A crucial study on Ad was published. At that time, because of the striking similarity between the C-terminal globular domain of $\mathrm{Ad}(\mathrm{gAd})$ and the subunit of complement factor C1q, it was named Acrp30 (Scherer et al., 1995).

Spiegelman and colleagues identified mouse Ad using mRNA differential display analysis, which confirmed that Ad expression was initiated by adipogenic differentiation process (Hu et al., 1996). Several key pieces of evidence in the early literature concerning this field indicated that Ad may be involved in the regulation of whole-body energy homeostasis (Hu et al., 1996). Using a cDNA library from human adipose tissue, other researchers determined that Ad is the most prevalent transcript, and they termed it the most abundant gene transcript 1 (APM1) (Maeda et al., 1996).

Major technological advancements enabled researchers to separate natural Ad into three types of complexes using more refined size separation methods. They include low molecular form of Ad (LMW) with trimeric structure, medium molecular form (MMW) with hexameric structure, and high molecular form of Ad (HMW, 12mer to 18mer) (Pajvani et al., 2004). Existing literature purports that Ad itself acts on pancreatic $\beta$ cells, as well as on cells of the pancreas, heart, liver, potential muscle, kidney, and several other types of cells in various tissues. Ad is instrumental in mediating other crucial effects: it can also inhibit hepatic gluconeogenesis by downregulating genes related to glucose production. Moreover, Ad can promote insulin sensitization and improve whole-body energy homeostasis through its localized function in key metabolic tissues. Ad exerts a strong protective effect on several pathological processes in various cells by inhibiting cell death and inflammatory process, thereby concomitantly promoting cell
Open Access https://doi.org/10.4062/biomolther.2021.089

This is an Open Access article distributed under the terms of the Creative Commons Attribution Non-Commercial License (http://creativecommons.org/licenses/by-nc/4.0/) which permits unrestricted non-commercial use, distribution, and reproduction in any medium, provided the original work is properly cited.
Received May 8, 2021 Revised Jul 29, 2021 Accepted Aug 20, 2021 Published Online Sep 28, 2021

\section{*Corresponding Authors}

E-mail: bioneer@skku.edu (Lee J), imsesame@gmail.com (Park SH) Tel: +82-31-290-7861 (Lee J), +82-44-860-2126 (Park SH) Fax: +82-31-290-7870 (Lee J), +82-44-866-6940 (Park SH) ${ }^{\dagger}$ The first three authors contributed equally to this work. www.biomolther.org 

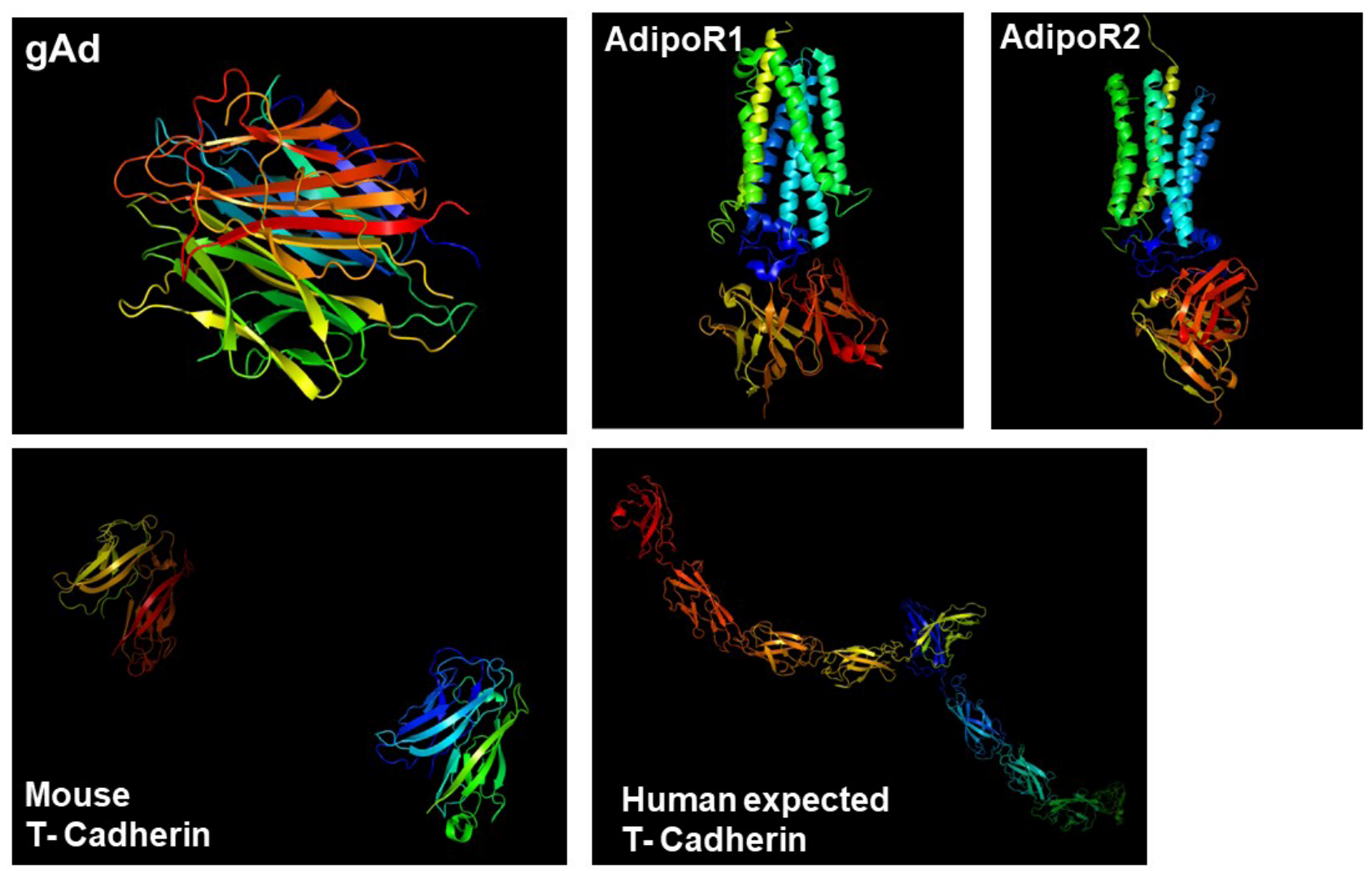

Fig. 1. Structure of globular adiponectin and adiponectin receptors. gAd, globular adiponectin.

survival (Scherer, 2006; Deng and Scherer, 2010). Following the discovery of Ad as a fat-derived factor, researchers soon focused their attention on characterizing the Ad receptor. Kadowaki and colleagues succeeded in this goal. Through a series of classifications of fluorescent-activated cells, it was determined that the cDNA clone could act as a binding receptor of gAd. This molecule, termed AdipoR1, is generally expressed in the skeletal muscle and liver. After AdipoR1, another homologous sequence, termed AdipoR2, was isolated; its expression was relatively limited to within the liver. The two receptors showed a remarkably high degree of similarity. Both R1 and R2 are intact membrane proteins. According to the Scatchard diagram and ligand-binding analysis, AdipoR1 can serve as a binding receptor for gAd and full-length Ad (fAd). AdipoR2 shows medium affinity toward gAd and fAd molecules (Yamauchi et al., 2003). In the past 20 years, Ad has been widely investigated and studied. It is established that Ad plays various roles in several organs, and these roles are mainly realized through the interaction between the two receptors of Ad. However, challenges in the field persist, and there are several unknown aspects of Ad that need to be elucidated (Wang and Scherer, 2016). In the present review, we focused on the interaction between Ad and skin based on existing experiments and studies. On this basis, four types of cells are described in detail: melanocytes, fibroblasts, keratinocytes, and immune cells.

\section{ADIPONECTIN}

Ad is an adipocyte-derived cytokine, also referred to as Acrp30 and AdipoQ. It is encoded by ADIPOQ in humans (Maeda et al., 1996). Ad is composed of 247 amino acids. There are four different domains, the first being a signal sequence for the extracellular secretion. The second is the hypervariable region that varies among species. The third is a collagenous stalk region consisting of 65 amino acids. The last is a globular domain (Shapiro and Scherer, 1998). Ad exists both as a $30 \mathrm{kDa}$ full-length molecule and a small-sized fragment containing the gAd (Fig. 1) (Wang and Scherer, 2016). fAd resembles the complement $1 Q(C 1 Q)$ factors, whereas the tertiary structure of the globular domain shows a high degree of similarity with members of the tumor necrosis factor (TNF) family (Shapiro and Scherer, 1998). Ad comprises an asymmetric trimer of three identical monomers. There are three distinct complex forms, namely HMW, MMW, and LMW in native Ad. The distribution of complexes may contribute to different downstream biological effects. Ad may directly interact with its receptors through the interface at the apex, which is mostly hydrophilic (Pajvani et al., 2003). Certain receptors bind to Ad (Table 1). Two receptors, namely AdipoR1 and AdipoR2, are homologous to the $\mathrm{G}$ protein-coupled receptors; one receptor resembles $\mathrm{CDH} 13$, a cadherin family receptor (Yamauchi et al., 2003; Hug et al., 2004). The receptors possess different affinities toward diverse forms of Ad and have distinct tissue specificities (Fang and Sweeney, 2006). When the receptor binds to Ad, it impacts the downstream target AMP kinase 
Table 1. Adiponectin receptors

\begin{tabular}{|c|c|c|c|}
\hline Receptor & Affinity toward adiponectin & Expression site & Feature \\
\hline AdipoR1 & $\begin{array}{l}\text { High affinity toward globular adiponectin } \\
\text { Can bind to full-length adiponectin }\end{array}$ & $\begin{array}{l}\text { Ubiquitous } \\
\text { Especially skeletal muscle and liver }\end{array}$ & Integral membrane protein \\
\hline AdipoR2 & $\begin{array}{l}\text { Intermediate affinity toward both globular } \\
\text { adiponectin and full-length adiponectin }\end{array}$ & Restricted to liver & Integral membrane protein \\
\hline T-cadherin & $\begin{array}{l}\text { Binds to the MMW and HMW forms of } \\
\text { adiponectin }\end{array}$ & $\begin{array}{l}\text { Endothelial cell } \\
\text { Smooth muscle cell } \\
\text { Attached to the plasma membrane by } \\
\text { glycosyl phosphatidylinositol anchor }\end{array}$ & $\begin{array}{l}\text { Interacts with eukaryotic post-trans- } \\
\text { lational modified adiponectin } \\
\text { Does not interact with globular or } \\
\text { bacterial-produced adiponectin }\end{array}$ \\
\hline
\end{tabular}

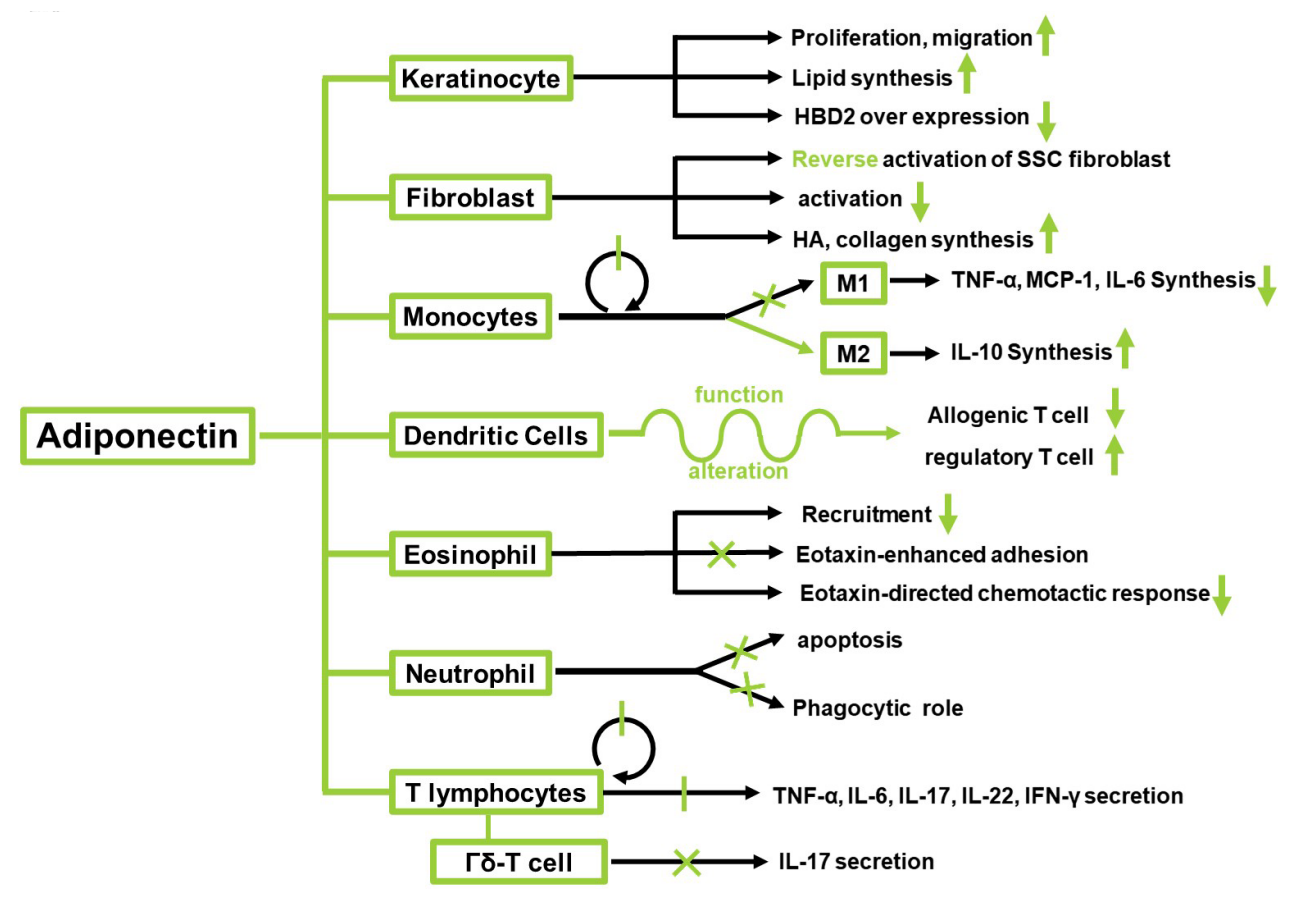

Fig. 2. Effects of adiponectin on various types of cells in skin.

(Bonnard et al., 2008). Ad is known to modulate numerous metabolic events such as regulation of glucose and fatty acid (Díez and Iglesias, 2003). However, the role of Ad in skin cells is relatively unknown. Therefore, in the present review, we focused on the function of Ad in keratinocytes, melanocytes, fibroblasts, and immune cells in the skin (Fig. 2, Table 2).

\section{RELATIONSHIP BETWEEN ADIPONECTIN AND SKIN CELLS}

\section{Effects of adiponectin on keratinocytes}

Keratinocytes constitute more than $90 \%$ of the cell population of the epidermis, the outermost part of the skin (Zeng et al., 2017). The main function of keratinocytes is the establishment of a physical barrier against environmental stresses to protect our body (Yuki et al., 2011). Therefore, it is important to repair the wounds in the skin to fill the gap created by the wound. Ad regulates multiple biological activities under various disease conditions of the whole body (Chandran et al., 2003; Achari and Jain, 2017) also known to influence cutaneous wound healing. Ad regulates wound healing in the skin through promotion of proliferation and migration of keratinocytes. Ad receptors are expressed in keratinocytes; Ad promotes the proliferation and migration of keratinocytes by activating ERK. The Ad -induced ERK signaling pathway is mediated by AdipoR1 and AdipoR2 (Shibata et al., 2012). Ad also impacts keratinocyte lipid synthesis from the viewpoint of skin barrier function. Researchers determined that Ad facilitates an increase in keratinocyte intracellular and reconstructed epidermal lipid content, using lipid staining. The levels of ceramide and sphingosine, the downstream lipid-derivative metabolites, were also elevated. They attempted to define the underlying metabolic pathway of Ad by suppressing SIRT1 and inhibiting Ad receptors. Finally, they determined that $\mathrm{Ad}$ enhances the expression of the $\mathrm{Ad}$ signaling molecule, SIRT1, as well as nuclear hormone receptors such as peroxisome proliferator-activated receptors and liver $X$ receptor- $\alpha$, thereby enhancing lipid synthesis and 
Table 2. Effects of adiponectin on various types of cells present in the skin

\begin{tabular}{|c|c|c|}
\hline Cell & Effects of Adiponectin on cells & References \\
\hline Keratinocyte & $\begin{array}{l}\text { Promotes cell proliferation and migration via ERK activation } \\
\text { Effects on differentiation through enhancing lipid synthesis } \\
\text { Anti-photoaging effect via downregulation of p38 and JNK/SAPK MAPK } \\
\text { signaling }\end{array}$ & $\begin{array}{l}\text { Shibata et al., } 2012 \\
\text { Hong et al., } 2019 \\
\text { Kim et al., } 2016\end{array}$ \\
\hline Melanocyte & $\begin{array}{l}\text { Full-length adiponectin inhibits melanogenesis via AMPK activation } \\
\text { Globular adiponectin stimulates melanogenesis via AMPK-p38 MAPK, CREB } \\
\text { signaling }\end{array}$ & $\begin{array}{l}\text { Bang et al., } 2017 \\
\text { Kim et al., } 2018\end{array}$ \\
\hline Fibroblast & $\begin{array}{l}\text { Increasing HA and collagen production in a concentration-dependent manner } \\
\text { and HA synthases 1,2,3 gene expression } \\
\text { Attenuating CTGF-induced keloid fibroblast progression by inhibiting AMPK, } \\
\text { p38 MAPK, ERK signaling } \\
\text { Decreasing the activation of fibroblasts and reversing the activation pheno- } \\
\text { type of systemic sclerosis fibroblasts }\end{array}$ & $\begin{array}{l}\text { Yang et al., } 2013 \\
\text { Iwayama et al., } 2012 \\
\text { Marangoni et al., } 2017\end{array}$ \\
\hline Macrophage & $\begin{array}{l}\text { Suppressing macrophage proliferation } \\
\text { Activating M2 instead of M1 differentiation }\end{array}$ & $\begin{array}{l}\text { Hui et al., } 2015 \\
\text { Tsatsanis et al., 2005; Park et } \\
\text { al., } 2007\end{array}$ \\
\hline Dendritic cell & $\begin{array}{l}\text { Role in DC differentiation remains controversial } \\
\text { Alters DC phenotype } \\
\text { Alters DC function to reduce allogenic T-cell proliferation }\end{array}$ & $\begin{array}{l}\text { Tsang et al., 2011; Jung et al., } \\
\text { 2012; Li et al., } 2012 \\
\text { Li et al., } 2012 \\
\text { Tsang et al., 2011; Li et al., } \\
2012\end{array}$ \\
\hline Neutrophil & $\begin{array}{l}\text { Full-length adiponectin blocks neutrophil phagocytosis } \\
\text { Inhibits neutrophil apoptosis }\end{array}$ & $\begin{array}{l}\text { Wensveen et al., } 2015 \\
\text { Rossi and Lord, } 2013\end{array}$ \\
\hline Eosinophil & $\begin{array}{l}\text { Negatively regulates recruitment of eosinophils } \\
\text { Eotaxin-enhanced adhesion is inhibited by adiponectin pretreatment } \\
\text { Eotaxin-directed chemotactic responses are diminished }\end{array}$ & $\begin{array}{l}\text { Rossi and Lord, } 2013 \\
\text { Yamamoto et al., } 2013\end{array}$ \\
\hline Natural Killer (NK) cell & Still controversial & $\begin{array}{l}\text { Takemura et al., 2007; Shi- } \\
\text { bata et al., } 2015\end{array}$ \\
\hline T lymphocytes & $\begin{array}{l}\text { Suppresses TNF- } \alpha \text {, IL-17, IL-22 secretion } \\
\text { Inhibits IL-17 producing activation of } \gamma \delta ~ T \text { cells }\end{array}$ & $\begin{array}{l}\text { Takahashi and lizuka, 2012; } \\
\text { Jasinski-Bergner et al., } 2017 \\
\text { Shibata et al., } 2015\end{array}$ \\
\hline
\end{tabular}

keratinocyte cell differentiation. This would aid in maintaining the homeostasis of the skin barrier (Hong et al., 2019). There is also evidence of a link between Ad and psoriasis. Psoriasis is a chronic inflammatory disease that is influenced by various factors. It is characterized by hyperproliferation and modified differentiation of keratinocytes (Krueger and Ellis, 2005; Nestle, 2008). Researchers focused on adipokines and evaluated the relationship between adipose tissue cytokines and disease severity. In a study researchers enrolled 42 psoriasis patients, in addition to 42 healthy individuals, who constituted a control group. Ad levels in the psoriasis patient group were significantly lower than those in the control group. The results showed that the anti-inflammatory effects of Ad are diminished in psoriasis patients, possibly accelerating the inflammatory process. In addition, a significant linear relationship between Ad levels and Psoriasis Area Severity Index (PASI) score-an indicator of disease severity-was observed. However, the relationship between Ad and psoriasis severity, as well as the cause-effect relationship between psoriasis and adipokine levels, needs to be clarified (Sereflican et al., 2016).

The anti-inflammatory effects of Ad also impact the inflammatory response-mediated premature senescence of keratinocytes. hBD2 overexpression was found in older individuals and under conditions of UV exposure (Gläser et al., 2009). UV irradiation influences calcium influx in keratinocytes and induces the production of intracellular reactive oxygen species (ROS) (Masaki et al., 2009). ROS mediate various cellular events, including the mitogen-activated protein kinase (MAPK) activation and the induction of DNA damage, leading to cellular senescence and hBD2 overexpression. Therefore, the ROS-scavenging ability of Ad could contribute to the prevention of oxidative stress-mediated DNA damage and the attenuation of unregulated production of hBD2.

\section{Effects of adiponectin on melanocytes}

Melanocytes are skin cells-located in the human epidermis-that are involved in producing the human skin pigment melanin (Cichorek et al., 2013). Tyrosinase and tyrosine-related protein 1 and 2 are involved in melanogenesis; adenosine monophosphate kinase, cyclic adenosine monophosphate response element-binding protein (CREB), p38 mitogen-activated protein kinases, and mitogen-activated protein kinase regulate MITF expression.

A few years ago, it was reported that Ad impacts melanocytes, regulating both their stimulation and inhibition. Interestingly, fAd exerts an anti-melanogenic effect; in contrast, gAd 


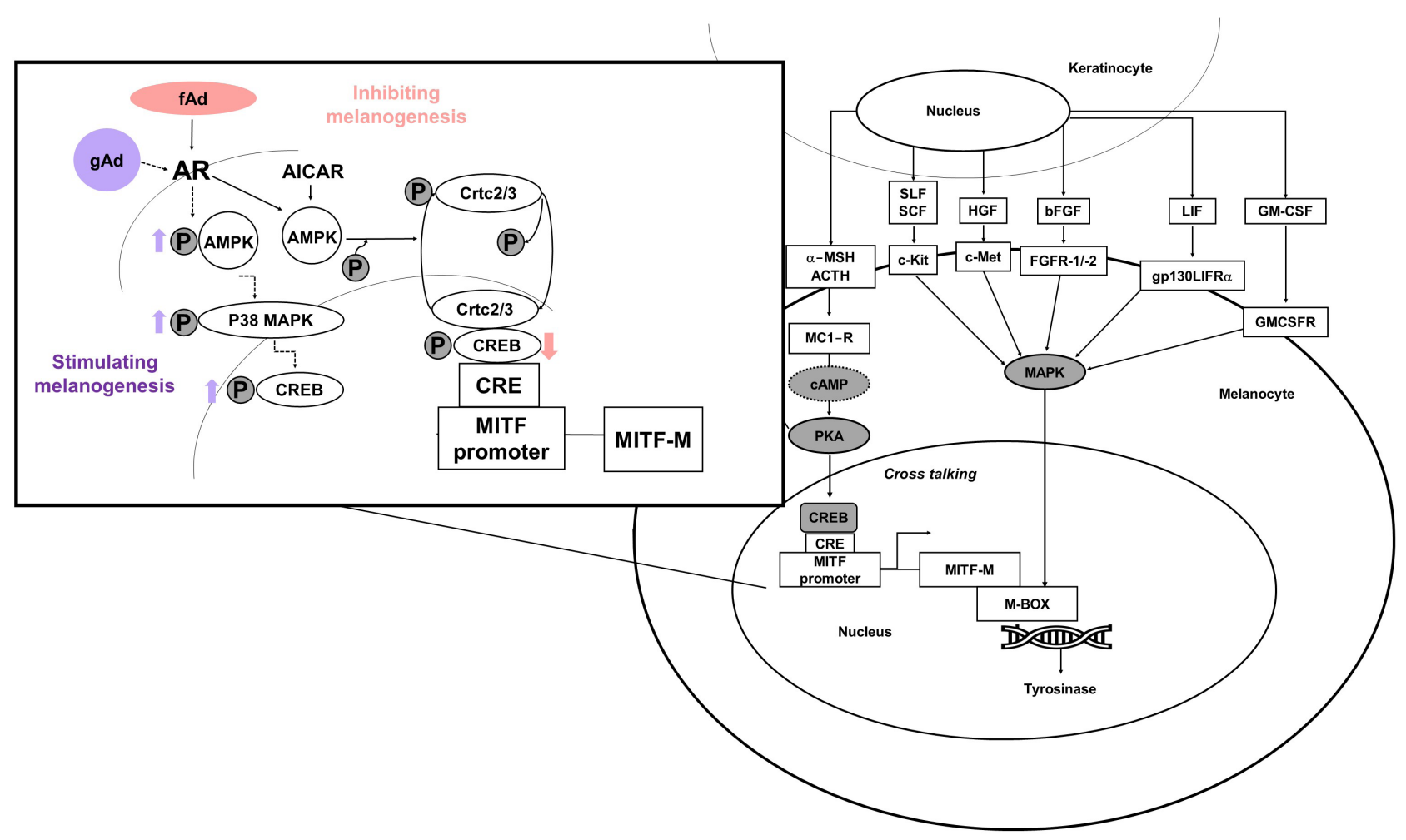

Fig. 3. Simple scheme of adiponectin action mechanisms in melanogenesis.

enhances melanogenesis (Fig. 3) (Bang et al., 2017; Kim et al., 2018).

Ad inhibits melanin synthesis via AMP-activated protein kinase (AMPK) activation. Furthermore, Bang et al. (2017) clearly demonstrated that CRTC2/3 and CREB co-operatively regulate MITF mRNA expression. They also reported that AMPK activation-through the induction of CRTC inhibitory phosphorylation-inhibits MITF expression (Bang et al., 2017).

In contrast, the globular domain of Ad induces melanogenesis and melanin synthesis is mediated by AMPK-p38 MAPK and CREB signaling. However, PKA signaling is independent of gAd (Kim et al., 2018). In addition, Mantzoros et al. (2007) observed a significant inverse relationship between serum Ad levels and melanoma risk in a case-control study, although this was not significant. Ad exerted anti-carcinogenic effects on other carcinoma cells, whereas it did not influence on melanoma cell proliferation in in vitro studies (Sun and Lodish, 2010). On the contrary, inhibition of tumor growth has been demonstrated for melanoma in animal studies. Ad has also been implicated in negative regulation of the growth of melanoma xenografts. The underlying mechanism of Ad may involve infiltrating macrophage into tumor tissue because tumors from Ad knockout mice exhibit reduced macrophage numbers (Sun and Lodish, 2010). Nevertheless, it remains unclear whether there is any impact on skin pigmentation in individuals with variations in AdipoR1 or AdipoR2 at the genetic level. Followup experiments are also necessary in ex vivo and in vivo models of hyper pigmentary disease (Tobin, 2018). Revealing the mechanisms governing the regulation of melanogenesis by Ad represents an important strategy for identifying therapeutic targets for hyperpigmentary skin disorders. These targets can then be leveraged in skin-whitening products, which are one of the major driving forces in the biocosmetic market.

\section{Effects of adiponectin on fibroblasts}

Fibroblasts are the most common cells in the connective tissue; each subgroup of fibroblasts is distinguished by its unique function (Driskell and Watt, 2015). One of the most important functions of fibroblasts is to synthesize the extracellular matrix (ECM), which contributes to maintaining the structural integrity of most tissues (Yang et al., 2013; Lynch and Watt, 2018). Type I collagen is the major component of the ECM in the skin and is composed of two $\alpha 1$ (I) chains and one $\alpha 2(\mathrm{I})$ chain, encoded by $C O L 1 A 1$ and $C O L 1 A 2$, respectively (Woodley, 2017). Hyaluronan (HA) is abundantly expressed in the dermis and contributes to a wide range of cellular functions, including proliferation, migration, adhesion, and differentiation.

It has been reported that Ad boosts HA and collagen production by dermal fibroblasts. Additionally, increase in HA synthases (HAS)2 expression has been observed (Yang et al., 2013). Moreover, Luo et al. discussed the role of Ad in keloid progression (Iwayama et al., 2012). The key phenotypic characteristics of keloid fibroblasts includes cell migration, hyperproliferation, and excess ECM accumulation. The authors proposed that Ad inhibits CTGF-induced keloid fibroblast proliferation, migration, and ECM production by attenuating CTGF-induced phosphorylation of p38 MAPK, ERK, and AMPK. Moreover, it was discovered that the AMPK, p38 MAPK, and ERK signaling pathways are involved in Ad-mediated CTGFinduced keloid fibroblast proliferation, migration, as well as 
ECM production (Iwayama et al., 2012).

In another experiment, it was confirmed that Systemic sclerosis (SSC) skin fibrosis was related to the injury of Ad signal in the injured tissue (Marangoni et al., 2017). SSC is a chronic fibrodegenerative disease, characterized by dermal fibrosis, which eventually leads to the destruction of organ structure. Ad is the most abundant circulating fat factor in SSC patients. The level of Ad is decreased in diffuse cutaneous SSC patients, which is negatively correlated with disease activity, severity, and course. Ad simultaneously diminished the activation of fibroblasts and reversed the activation phenotype of SSC fibroblasts. These results revealed that the expression and dysfunction of endogenous Ad is a key pathogenic mechanism underlying skin fibrosis, with a strong negative regulatory effect on fibrosis. Enhancing cell Ad signaling may be employed as a novel strategy for treating SSC. Based on their tolerability and favorable pharmacokinetic properties, peptides that activate the Ad pathway may prove to be a feasible tool for further development of anti-fibrosis therapy.

\section{RELATIONSHIP BETWEEN ADIPONECTIN AND SKIN AGING}

Skin aging is influenced by intrinsic and extrinsic factors. Intrinsic (natural) aging is a gradual decrease in collagen production, decreased elastin elasticity, and decreased turnover rates. The criteria for intrinsic aging include fine wrinkles, loss of fat, and thin skin. Extrinsic aging is caused by external energies, forces, and factors such as ultraviolet violet radiation, gravity, and smoking (Sjerobabski-Masnec and Šitum, 2010). Urban particulate matter and blue light have also recently emerged as causes of skin aging (Kwon et al., 2018; Yoo et al., 2020).

The relationship between aging and Ad has been investigated (Iwabu et al., 2015). Ad and AdipoR expression is skin aging-dependently reduced and an Ad deficiency promotes skin aging (Akazawa et al., 2011). This indicates that $\mathrm{Ad}$ is related to skin aging. Young skin is characterized by low transepidermal water loss (TEWL), and aging skin gradually loses moisture (Ngatu et al., 2017). Hyaluronic acid, which is mainly associated with TEWL, is supplied by keratinocytes and fibroblasts, and helps to maintain homeostasis by retaining moisture in the skin (Papakonstantinou et al., 2012). Full-length Ad plays an important role in fibroblast HA metabolism and increases HA expression in the dermis (Akazawa et al., 2011), which also helps to retain moisture in the skin (Papakonstantinou et al., 2012).

The response to external wound healing becomes slower as skin ages (Wang and Dreesen, 2018). Wounds to the skin result in increased Ad generation, which slows the rate of keratinocyte proliferation in the epidermis during healing and promotes recovery (Kawai et al., 2008). Photoaging accounts for a large proportion of extrinsic aging. Photoaging results in increased MMP-1 expression in the skin (Pittayapruek et al., 2016). This can be suppressed by increased Ad production that attenuates skin aging via suppressing p38 and JNK/ SAPK MAPK signaling in UVB-mediated premature senescent keratinocytes. These results indicate that Ad might act as an anti-photoaging agent in the skin (Kim et al., 2016). Overall, the beneficial effects of Ad are improved skin health and inhibited skin aging.

\section{ADIPONECTIN AND IMMUNITY}

\section{Immunity of skin}

The skin acts as an excellent physiological barrier to external invasive factors, such as viruses, bacteria, and even small dust particles. As the skin is the first shield against pathogen infection, it is easy to presume that it is only involved in innate immunity, i.e., macrophages, neutrophils, etc. However, the skin also serves as a platform for recruiting components of the adaptive immune system, namely $T$ cells -in particular CD4+, CD8+-and skin-resident memory $\gamma \delta$ T cells. Further, there are skin-specific immune cells, Langerhans cells, which are a mass of dendritic cells only located in the epidermis, and CLA+ memory $T$ cells, which differentiate into either the T helper cells (Th) 1 or Th2 subtype depending on cytokine stimulation (Clark et al., 2006).

\section{Innate immunity and adiponectin}

Innate immunity is the first line of defense against pathogens and it is distinguished by a rapid, non-specific response. It comprises several types of cells, including mast antigenpresenting cells (APCs), neutrophils, natural killer (NK) cells, dendritic cells (DCs), macrophages, and ILC families. These cells are key regulators of energy and glucose homeostasis (Brestoff et al., 2015). Ad colocalizes with TLR1, 2, and 4 proteins in human adipocytes, and TLR4 is the most abundantly expressed among the TLR families in human adipose tissue (Vitseva et al., 2008). In addition, Ad regulates inflammasome activation via the AMPK signaling pathway, and gAd inhibits lipopolysaccharide (LPS)-primed inflammasome activation in macrophages via autophagy induction (Kim et al., 2017). Ad can similarly abolish NLRP3 inflammasome activation via the AMPK-JNK/Erk1/2-NF-кB/ROS signaling pathways (Dong et al., 2020). These results suggest that Ad plays a dynamic role in the regulation of inflammation and innate immunity via the $\mathrm{NF}-\kappa \mathrm{B}$ signaling pathway.

\section{RELATIONSHIP BETWEEN C1Q AND ADIPONECTIN}

Complement component 1q (C1q) participates in the classical pathway as a component of the innate immunity system. The CLR (collagen-like region) of $\mathrm{C} 1 \mathrm{q}$ is the scaffold for $\mathrm{C} 1 \mathrm{~s}$ and $\mathrm{C} 1 \mathrm{r}$, which comprise a calcium-dependent $\mathrm{C} 1$ complex. Complement component $1 \mathrm{q}$ recognizes and binds to immunoglobulin, which induces the complement cascade to start. Ad contains a C1q-like globular domain. The structural similarity between $\mathrm{Ad}$ and $\mathrm{C} 1 \mathrm{q}$ indicates that $\mathrm{Ad}$ participates in innate immunity. In fact, $\mathrm{C} 1 \mathrm{q}$ and $\mathrm{Ad}$ both promote the removal of apoptotic cells by activating Mer tyrosine kinase, which regulates autoimmunity (Galvan et al., 2014).

\section{PRO- OR ANTI-INFLAMMATORY FUNCTION OF ADIPONECTIN}

Ad usually acts as an anti-inflammatory factor exerting antiapoptotic, inflammatory, and oxidative effects (Cappellano et al., 2018). However, when LPS infiltrates, it helps cells to produce pro-inflammatory stimuli. Following LPS stimuli, Ad shows pro-inflammatory effects during the initial response (Yamaguchi et al., 2005; Mandal et al., 2011). Ad induces the 
expression of pro-inflammatory cytokines and nitric oxide synthase in human cartilage cell chondrocytes (Lago et al., 2008), indicating that it possesses both anti-inflammatory and proinflammatory properties (Monks et al., 2019). Ad expression is linked to other adipokines, leptin, resistin, or other endothelial factors, including endothelin-1 (Stochmal et al., 2020). They up- or downregulate each other, enhancing or inhibiting the activities of immune cells (Gerkowicz et al., 2012; Li et al., 2012; Takahashi and lizuka, 2012; Stochmal et al., 2020). From this section onward, we have summarized the roles of Ad in regulating innate immunity and adaptive immunity, especially T cells.

\section{MACROPHAGES AND MONOCYTES}

The relationship between macrophages and Ad has been well investigated, with the most studied aspects being the functions of Ad in innate immunity. M1 macrophages-classically activated macrophages-promote both the production of pro-inflammatory cytokines and obesity-induced insulin resistance and type 2 diabetes (Nguyen et al., 2011; Mantovani et al., 2013). Otherwise, M2 macrophages, alternatively activated macrophages, are polarized by IL- 4 and IL-13 and contribute to induction of tissue repair, blockade of inflammatory responses, and the promotion of oxidative metabolism (Wolf et al., 2004; Wulster-Radcliffe et al., 2004). Numerous studies have demonstrated that Ad exerts anti-inflammatory effects. First, it downregulates M1 markers, such as MCP-1, IL-6, and TNF- $\alpha$ (Ohashi et al., 2010; Odegaard and Chawla, 2011; Hui et al., 2015). Differentiation of macrophages-which are activated by the classical pathway-is triggered by Ad deficiency (Hui et al., 2015). Moreover, Ad blocks inflammatory effects by suppressing macrophage proliferation and by promoting the apoptosis of myelomonocytic progenitors. Second, it induces M2 proliferation by alternative activation (Tsatsanis et al., 2005). fAd mediates the shift in macrophage polarization toward the M2 phenotype via the IL-4/STAT6 pathway (Li et al., 2012). Because M2 macrophages play an important role in the browning of white adipose tissue (WAT) through secretion of norepinephrine, thereby providing a novel mechanism by which Ad promotes a cold-induced browning effect in (subcutaneous) adipose tissue (Park et al., 2007), thus demonstrating a metabolic relationship.

Ad receptors play different roles in macrophages depending on their type. Macrophages bear AdipoR1, AdipoR2, and CDH13, with a high abundance of AdipoR1 (Mandal et al., 2011). AdipoR1 primarily binds to gAd and suppresses proinflammatory cytokine expression, thereby mediating NF-kB Ad suppressing activation (Chedid et al., 2012). AdipoR2 is required for fAd-mediated M2 polarization (Medoff et al., 2009). $\mathrm{CDH} 13$, especially activated by cold exposure, is required for M2 proliferation (Park et al., 2007). However, suppression of these receptors does not result in a prominent effect on THP-1 cell uptake, although macrophages and their progenitors, monocytes, bear all these receptors, hence implicating other intermediate mechanisms. Further studies are required because AdipoR1 expression in monocytes remains a contentious topic (Jung et al., 2012; Jasinski-Bergner et al., 2017). The opposite conclusion may be derived from the low number of samples, which requires additional studies to define the properties of Ad in monocytes.

\section{DENDRITIC CELLS (DCS)}

DCs are one of important APCs. DCs exert a strong effect on psoriasis. DCs secrete IL-20, IL-23, TNF- $\alpha$, and IL-23, thereby promoting the differentiation of Th17 cells, which stimulate keratinocyte proliferation and secrete IL-17A, IL-17F, and IL-22 (Gerkowicz et al., 2012; Takahashi and lizuka, 2012; Shibata et al., 2015). DC counts are enhanced by Th17 through the boosting of IL-1, IL-8, and TNF- $\alpha$ levels via the upregulation of keratinocyte IL-8 secretion, which in turn upregulates IL-17 and IL-22 production (Shibata et al., 2015).

The effects of $\mathrm{Ad}$ on dendritic cells remain controversial (Tsang et al., 2011; Jung et al., 2012; Li et al., 2012). A prior study on Ad involving the blocking of DC activity revealed impaired activation of allogenic $\mathrm{T}$ cells following Ad treatment (Tsang et al., 2011). A similar study showed that Ad directly impacts the DC phenotype, without considerable change in differentiation; conversely, the indirect effects alter DC function to reduce allogenic T-cell proliferation and enhance regulatory T-cell production (Li et al., 2012).

Another study postulating the opposite theory specified DC activation via $\mathrm{C} \gamma / \mathrm{JNK} / \mathrm{NF}-\mathrm{kB}$, resulting in Th1 and Th17 polarization depending on the Ad receptor type (Jung et al., 2012); this indicates that Ad exerts a dose-and time-dependent effect (Luo and Liu, 2016). Other studies have shown low levels of Ad in psoriasis (Takahashi and lizuka, 2012), which may indicate that Ad downregulates DCs. To clarify the action of Ad on DCs, further studies with well-considered models and experimental designs are needed.

\section{BLOOD CELLS}

\section{Neutrophils}

Blood cells are rich in neutrophils, of which granulocytes are the most abundant type. The mechanism of their response to bacteria involves antimicrobial granules that fuse with phagosomes and cause neutrophils to engulf and kill bacteria. Adiponectin negatively regulates neutrophils since most of them express AdipoR1 and AdipoR2, (Amulic et al., 2012). Specifically, fAd AMPK-dependently blocks the phagocytic role of neutrophils through the suppression of NADPH oxidase and ROS production (Wensveen et al., 2015). Ad also suppresses neutrophil apoptosis by activating ERK 1/2 MAP kinase, PKB, and AMP kinase (Rossi and Lord, 2013). Skin transplantation into Ad-knockout (KO) mice results in an expanded neutrophil population that induces an inflammatory response, indicating that an Ad deficiency impairs granulopoiesis (Li et al., 2012; Masamoto et al., 2016). Furthermore, Ad cleavage results in the production of gAd fragments in monocytic THP-1 and U937 cell lines (Wilk et al., 2013). This process is notably mediated by leukocyte (neutrophil) elastase.

\section{Eosinophils}

Eosinophils are the second most abundant type of granulocytes; they protect against parasites and modulate innate and adaptive immunity through various mechanisms including the initiation and propagation of various inflammatory responses, the induction of $\mathrm{T}$ cell activation, and the secretion of cytokines such as IL-6, IL-12, and TNF- $\alpha$ (Rothenberg and Hogan, 2006) Human eosinophils express AdipoR1 and AdipoR2 (Yamamoto et al., 2013), and Ad negatively regulates 
eosinophil recruitment (Rossi and Lord, 2013). Although Ad does not affect eosinophil survival or CCR3 expression, Ad suppresses eotaxin-induced adhesion and decreases eotaxin-directed chemotactic responses, which results in reduced calcium signaling rather than altered surface receptor expression (Yamamoto et al., 2013). However, AMPK activation in Ad $\mathrm{KO}$ mice first slightly decreased and then increased eosinophil counts, suggesting a relationship between Ad and AMPK (Li et al., 2012). Eosinophils comprise a source of Ad (Withers et al., 2017). Impaired adipocyte enlargement in eosinophil-deficient mice indicates a relationship between eosinophils and adipocyte maturation (Lee et al., 2018).

\section{NATURAL KILLER CELLS}

NK cells are lymphocytes that play major roles in innate immunity as they can differentiate self from non-self and exert cytotoxicity against target cells (infected and tumorous cells). These cells do not need prior antigen exposure to exert anti-tumor actions, and their major responses target tumors and viruses. Natural killer cells function via unique signaling pathways that provide exclusive methods of genetic manipulation that enhance their effector functions (Abel et al., 2018). Natural killer cells also mediate pro-inflammatory responses by promoting M1 activation (Waki et al., 2005).

Human NK cells expressing CD56 dim also express AdipoRs, while CD56 high NK cells are AdipoR-negative. A small population of murine NK cells expresses surface AdipoR, whereas most murine NK cells store AdipoRs intracellularly (Wilk et al., 2013). A modulating role of Ad in NK cells has not yet been clarified (Shibata et al., 2015). That is, whether Ad enhances or reduces NK cell counts remains controversial (Takemura et al., 2007; Shibata et al., 2015). In addition, evidence has yet to show that AdipoRs contribute to the role of Ad in the regulation of NK cells (Kim et al., 2006).

\section{ADAPTIVE IMMUNITY: T CELL}

T cells express the AdipoR1 and AdipoR2 (Cheng et al., 2012), confirming that Ad has a strong relationship with adaptive immunity, especially with certain types of T cells. Ad inhibits the secretion of TNF- $\alpha$, IL-17, and IL-22 by T lymphocytes; this phenomenon highlights the anti-inflammatory role of Ad (Takahashi and lizuka, 2012; Jasinski-Bergner et al., 2017). It also inhibits the enhancement of T-cell proliferation via the AMPK/p38 MAPK inhibitor (Li et al., 2012). In Th, Ad specifically regulates Th1 cells, which express high levels of ADIPOR1 (Jasinski-Bergner et al., 2017) and Th22 depending on its situation (Yamashita et al., 2018). Regulatory T lymphocytes (Tregs) - the differentiation of which varies depending on whether they express a specific set of cytokines or not-inhibit the inflammatory reaction and antigen tolerance (Gerkowicz et al., 2012). Ad may regulate Tregs by mediating the expression of TGF- $\beta$, which affects Tregs (Yamashita et al., 2018).

$\mathrm{IL}-17$ production by $\gamma \delta-\mathrm{T}$ cells is inhibited by Ad; furthermore, the rate of infiltration of $\gamma \delta$-T cells into dermal tissue is accelerated in Ad KO mice through direct interaction with AdipoR1, resulting in upregulated IL-17 (Shibata et al., 2015). Cytotoxic T lymphocytes express ADIPOQ, and high levels of
Ad population may imply a correlation with Ad, which warrants further research (Jasinski-Bergner et al., 2017). In response to LPS, Ad inhibits the expression of three T-lymphocyte chemoattractants that LPS-derived macrophages express (Steffens and Mach, 2008).

\section{CONCLUSIONS}

In the present study, we reviewed the functions of Ad in various types of cells of the skin. Ad is known to upregulate ECM production by dermal fibroblasts and anti-fibrotic factors concomitantly. It has been proved that Ad plays an essential role in renal fibrosis, periodontitis, and fibrosis diseases. In particular, a strong negative regulatory effect on fibrosis facilitates the development of novel anti-fibrosis therapy. Ad also enhances skin barrier function in keratinocytes. The proliferation and migration of keratinocytes, as well as lipid synthesis by keratinocytes, are regulated by Ad. Clinical studies on psoriasis patients have shown a cause-effect relationship, which needs to be investigated further in future studies.

Indeed, it has been determined that melanogenesis is regulated by Ad under in vitro conditions, and its regulation could be leveraged in the development of skin-whitening products and therapeutic agents for hyperpigmentary skin disorders. Ad is also linked to immunity, as skin is the foremost barrier in contact with pathogens. Although it remains controversial whether Ad application is efficacious in certain types of immune cells, it is clearly known that Ad can act as an anti- and pro-inflammatory factor under spatial and temporal conditions in macrophages, and that it has a strong relationship with $T$ cells. The immune system works with sophisticated mechanisms; thus, further studies are required.

In conclusion, although the physiological roles of Ad are not fully understood, the present review demonstrates that $\mathrm{Ad}$ is involved in various aspects of cellular biology in the skin, indicating that it could be used as a molecular biomarker to treat skin disorders.

\section{CONFLICT OF INTEREST}

The authors have declared no conflicting interests.

\section{ACKNOWLEDGMENTS}

This study was supported by a grant from the Basic Science Research Program through the National Research Foundation of Korea (NRF) funded by the Ministry of Science and Technology Information and Communication (Grant No. 2020R1F1A1067731).

\section{REFERENCES}

Abel, A. M., Yang, C., Thakar, M. S. and Malarkannan, S. (2018) Natural killer cells: development, maturation, and clinical utilization. Front. Immunol. 9, 1869.

Achari, A. E. and Jain, S. K. (2017) Adiponectin, a therapeutic target for obesity, diabetes, and endothelial dysfunction. Int. J. Mol. Sci. 18, 1321.

Akazawa, Y., Sayo, T., Sugiyama, Y., Sato, T., Akimoto, N., Ito, A. and 
Inoue, S. (2011) Adiponectin resides in mouse skin and upregulates hyaluronan synthesis in dermal fibroblasts. Connect. Tissue Res. 52, 322-328.

Amulic, B., Cazalet, C., Hayes, G. L., Metzler, K. D. and Zychlinsky, A. (2012) Neutrophil function: from mechanisms to disease. Annu. Rev. Immunol. 30, 459-489.

Bang, S., Won, K. H., Moon, H. R., Yoo, H., Hong, A., Song, Y. and Chang, S. E. (2017) Novel regulation of melanogenesis by adiponectin via the AMPK/CRTC pathway. Pigment Cell Melanoma Res. 30, 553-557.

Bonnard, C., Durand, A., Vidal, H. and Rieusset, J. (2008) Changes in adiponectin, its receptors and AMPK activity in tissues of dietinduced diabetic mice. Diabetes Metab. 34, 52-61.

Brestoff, J. R., Kim, B. S., Saenz, S. A., Stine, R. R., Monticelli, L. A., Sonnenberg, G. F., Thome, J. J., Farber, D. L., Lutfy, K., Seale, P. and Artis, D. (2015) Group 2 innate lymphoid cells promote beiging of white adipose tissue and limit obesity. Nature 519, 242-246.

Cappellano, G., Morandi, E. M., Rainer, J., Grubwieser, P., Heinz, K., Wolfram, D., Bernhard, D., Lobenwein, S., Pierer, G. and Ploner, C. (2018) Human macrophages preferentially infiltrate the superficial adipose tissue. Int. J. Mol. Sci. 19, 1404.

Chandran, M., Phillips, S. A., Ciaraldi, T. and Henry, R. R. (2003) Adiponectin: more than just another fat cell hormone? Diabetes Care 26, 2442-2450.

Chedid, P., Hurtado-Nedelec, M., Marion-Gaber, B., Bournier, O., Hayem, G., Gougerot-Pocidalo, M. A., Frystyk, J., Flyvbjerg, A., El Benna, J. and Marie, J. C. (2012) Adiponectin and its globular fragment differentially modulate the oxidative burst of primary human phagocytes. Am. J. Pathol. 180, 682-692.

Cheng, X., Folco, E. J., Shimizu, K. and Libby, P. (2012) Adiponectin induces pro-inflammatory programs in human macrophages and CD4+ T cells. J. Biol. Chem. 287, 36896-36904.

Cichorek, M., Wachulska, M., Stasiewicz, A. and Tymińska, A. (2013) Skin melanocytes: biology and development. Postepy Dermatol. Alergol. 30, 30-41.

Clark, R. A., Chong, B., Mirchandani, N., Brinster, N. K., Yamanaka, K., Dowgiert, R. K. and Kupper, T. S. (2006) The vast majority of CLA+ T cells are resident in normal skin. J. Immunol. 176, 4431-4439.

Deng, Y. and Scherer, P. E. (2010) Adipokines as novel biomarkers and regulators of the metabolic syndrome. Ann. N. Y. Acad. Sci. 1212, E1-E19.

Díez, J. J. and Iglesias, P. (2003) The role of the novel adipocyte-derived hormone adiponectin in human disease. Eur. J. Endocrinol. $148,293-300$

Dong, Z., Zhuang, Q., Ye, X., Ning, M., Wu, S., Lu, L. and Wan, X. (2020) Adiponectin inhibits NLRP3 inflammasome activation in nonalcoholic steatohepatitis via AMPK-JNK/ErK1/2-NFKB/ROS signaling pathways. Front. Med. (Lausanne) 7, 546445.

Driskell, R. R. and Watt, F. M. (2015) Understanding fibroblast heterogeneity in the skin. Trends Cell Biol. 25, 92-99.

Fang, X. and Sweeney, G. (2006) Mechanisms regulating energy metabolism by adiponectin in obesity and diabetes. Biochem. Soc. Trans. 34, 798-801.

Galvan, M. D., Hulsebus, H., Heitker, T., Zeng, E. and Bohlson, S. S. (2014) Complement protein C1q and adiponectin stimulate Mer tyrosine kinase-dependent engulfment of apoptotic cells through a shared pathway. J. Innate Immun. 6, 780-792.

Gerkowicz, A., Pietrzak, A., Szepietowski, J. C., Radej, S. and Chodorowska, G. (2012) Biochemical markers of psoriasis as a metabolic disease. Folia Histochem. Cytobiol. 50, 155-170.

Gläser, R., Navid, F., Schuller, W., Jantschitsch, C., Harder, J., Schröder, J. M., Schwarz, A. and Schwarz, T. (2009) UV-B radiation induces the expression of antimicrobial peptides in human keratinocytes in vitro and in vivo. J. Allergy Clin. Immunol. 123 1117-1123

Hong, S. P., Seo, H. S., Shin, K. O., Park, K., Park, B. C., Kim, M. H., Park, M., Kim, C. D. and Seo, S. J. (2019) Adiponectin enhances human keratinocyte lipid synthesis via SIRT1 and nuclear hormone receptor signaling. J. Invest. Dermatol. 139, 573-582.

Hu, E., Liang, P. and Spiegelman, B. M. (1996) AdipoQ is a novel adipose-specific gene dysregulated in obesity. J. Biol. Chem. 271 10697-10703.
Hug, C., Wang, J., Ahmad, N. S., Bogan, J. S., Tsao, T. S. and Lodish, H. F. (2004) T-cadherin is a receptor for hexameric and high-molecular-weight forms of Acrp30/adiponectin. Proc. Natl. Acad. Sci. U.S.A. 101, 10308-10313.

Hui, X., Gu, P., Zhang, J., Nie, T., Pan, Y., Wu, D., Feng, T., Zhong, C., Wang, Y., Lam, K. S. and Xu, A. (2015) Adiponectin enhances coldinduced browning of subcutaneous adipose tissue via promoting M2 macrophage proliferation. Cell Metab. 22, 279-290.

Iwabu, M., Okada-Iwabu, M., Yamauchi, T. and Kadowaki, T. (2015) Adiponectin/adiponectin receptor in disease and aging. NPJ Aging Mech. Dis. 1, 15013.

Iwayama, T., Yanagita, M., Mori, K., Sawada, K., Ozasa, M., Kubota, M., Miki, K., Kojima, Y., Takedachi, M., Kitamura, M., Shimabukuro, Y., Hashikawa, T. and Murakami, S. (2012) Adiponectin regulates functions of gingival fibroblasts and periodontal ligament cells. $J$. Periodontal. Res. 47, 563-571.

Jasinski-Bergner, S., Büttner, M., Quandt, D., Seliger, B. and Kielstein, H. (2017) Adiponectin and its receptors are differentially expressed in human tissues and cell lines of distinct origin. Obes. Facts 10, 569-583.

Jung, M. Y., Kim, H. S., Hong, H. J., Youn, B. S. and Kim, T. S. (2012) Adiponectin induces dendritic cell activation via PLC $\gamma / J N K / N F-\kappa B$ pathways, leading to Th1 and Th17 polarization. J. Immunol. 188, 2592-2601.

Kawai, K., Kageyama, A., Tsumano, T., Nishimoto, S., Fukuda, K., Yokoyama, S., Oguma, T., Fujita, K., Yoshimoto, S., Yanai, A. and Kakibuchi, M. (2008) Effects of adiponectin on growth and differentiation of human keratinocytes-implication of impaired wound healing in diabetes. Biochem. Biophys. Res. Commun. 374, 269273.

Kim, K. Y., Kim, J. K., Han, S. H., Lim, J. S., Kim, K. I., Cho, D. H., Lee, M. S., Lee, J. H., Yoon, D. Y., Yoon, S. R., Chung, J. W., Choi, I., Kim, E. and Yang, Y. (2006) Adiponectin is a negative regulator of NK cell cytotoxicity. J. Immunol. 176, 5958-5964.

Kim, M., Park, K. Y., Lee, M. K., Jin, T. and Seo, S. J. (2016) Adiponectin suppresses UVB-induced premature senescence and hBD2 overexpression in human keratinocytes. PLoS ONE 11, e0161247.

Kim, M. J., Kim, E. H., Pun, N. T., Chang, J. H., Kim, J. A., Jeong, J. H., Choi, D. Y., Kim, S. H. and Park, P. H. (2017) Globular adiponectin inhibits lipopolysaccharide-primed inflammasomes activation in macrophages via autophagy induction: the critical role of AMPK signaling. Int. J. Mol. Sci. 18, 1275.

Kim, Y., Cho, J. Y., Oh, S. W., Kang, M., Lee, S. E., Jung, E., Park, Y. S. and Lee, J. (2018) Globular adiponectin acts as a melanogenic signal in human epidermal melanocytes. Br. J. Dermatol. 179, 689701.

Krueger, G. and Ellis, C. N. (2005) Psoriasis--recent advances in understanding its pathogenesis and treatment. J. Am. Acad. Dermatol. 53, S94-S100.

Kwon, K., Park, S. H., Han, B. S., Oh, S. W., Lee, S. E., Yoo, J. A., Park, S. J., Kim, J., Kim, J. W., Cho, J. Y. and Lee, J. (2018) Negative cellular effects of urban particulate matter on human keratinocytes are mediated by p38 MAPK and NF-kB-dependent expression of TRPV 1. Int. J. Mol. Sci. 19, 2660.

Lago, R., Gomez, R., Otero, M., Lago, F., Gallego, R., Dieguez, C., Gomez-Reino, J. J. and Gualillo, O. (2008) A new player in cartilage homeostasis: adiponectin induces nitric oxide synthase type II and pro-inflammatory cytokines in chondrocytes. Osteoarthritis Cartilage 16, 1101-1109.

Lee, E. H., Itan, M., Jang, J., Gu, H. J., Rozenberg, P., Mingler, M. K., Wen, T., Yoon, J., Park, S. Y., Roh, J. Y., Choi, C. S., Park, W. J., Munitz, A. and Jung, Y. (2018) Eosinophils support adipocyte maturation and promote glucose tolerance in obesity. Sci. Rep. 8, 9894.

Li, D., Tsang, J. Y., Peng, J., Ho, D. H., Chan, Y. K., Zhu, J., Lui, V. C., Xu, A., Lamb, J. R., Tam, P. K. and Chen, Y. (2012) Adiponectin mediated MHC class II mismatched cardiac graft rejection in mice is IL-4 dependent. PLOS ONE 7, e48893.

Luo, Y. and Liu, M. (2016) Adiponectin: a versatile player of innate immunity. J. Mol. Cell Biol. 8, 120-128.

Lynch, M. D. and Watt, F. M. (2018) Fibroblast heterogeneity: implications for human disease. J. Clin. Invest. 128, 26-35.

Maeda, K., Okubo, K., Shimomura, I., Funahashi, T., Matsuzawa, Y. 
and Matsubara, K. (1996) cDNA cloning and expression of a novel adipose specific collagen-like factor, apM1 (AdiPose Most abundant Gene transcript 1). Biochem. Biophys. Res. Commun. 221, 286-289.

Mandal, P., Pratt, B. T., Barnes, M., McMullen, M. R. and Nagy, L. E. (2011) Molecular mechanism for adiponectin-dependent M2 macrophage polarization: link between the metabolic and innate immune activity of full-length adiponectin. J. Biol. Chem. 286, 1346013469.

Mantovani, A., Biswas, S. K., Galdiero, M. R., Sica, A. and Locati, M. (2013) Macrophage plasticity and polarization in tissue repair and remodelling. J. Pathol. 229, 176-185.

Mantzoros, C. S., Trakatelli, M., Gogas, H., Dessypris, N., Stratigos, A., Chrousos, G. P. and Petridou, E. T. (2007) Circulating adiponectin levels in relation to melanoma: a case-control study. Eur. $J$. Cancer 43, 1430-1436

Marangoni, R. G., Masui, Y., Fang, F., Korman, B., Lord, G., Lee, J., Lakota, K., Wei, J., Scherer, P. E., Otvos, L., Yamauchi, T., Kubota, N., Kadowaki, T., Asano, Y., Sato, S., Tourtellotte, W. G. and Varga, J. (2017) Adiponectin is an endogenous anti-fibrotic mediator and therapeutic target. Sci. Rep. 7, 4397.

Masaki, H., Izutsu, Y., Yahagi, S. and Okano, Y. (2009) Reactive oxygen species in $\mathrm{HaCaT}$ keratinocytes after UVB irradiation are triggered by intracellular $\mathrm{Ca}(2+)$ levels. J. Invest. Dermatol. Symp. Proc. 14, 50-52.

Masamoto, Y., Arai, S., Sato, T., Yoshimi, A., Kubota, N., Takamoto, I. Iwakura, Y., Yoshimura, A., Kadowaki, T. and Kurokawa, M. (2016) Adiponectin enhances antibacterial activity of hematopoietic cells by suppressing bone marrow inflammation. Immunity 44, 14221433.

Medoff, B. D., Okamoto, Y., Leyton, P., Weng, M., Sandall, B. P., Raher, M. J., Kihara, S., Bloch, K. D., Libby, P. and Luster, A. D. (2009) Adiponectin deficiency increases allergic airway inflammation and pulmonary vascular remodeling. Am. J. Respir. Cell Mol. Biol. 41, 397-406.

Monks, M., Irakleidis, F. and Tan, P. H. (2019) Complex interaction of adiponectin-mediated pathways on cancer treatment: a novel therapeutic target. J. Cancer Metastasis Treat. 5, 24.

Nestle, F. O. (2008) Psoriasis. Curr. Dir. Autoimmun. 10, 65-75.

Ngatu, N. R., Tanaka, M., Ikeda, M., Inoue, M., Kanbara, S. and Nojima, S. (2017) Sujiaonori-derived algal biomaterials inhibit allergic reaction in allergen-sensitized RBL-2H3 cell line and improve skin health in humans. J. Funct. Biomater. 8, 37.

Nguyen, K. D., Qiu, Y., Cui, X., Goh, Y. P., Mwangi, J., David, T., Mukundan, L., Brombacher, F., Locksley, R. M. and Chawla, A. (2011) Alternatively activated macrophages produce catecholamines to sustain adaptive thermogenesis. Nature 480, 104-108.

Odegaard, J. I. and Chawla, A. (2011) Alternative macrophage activation and metabolism. Annu. Rev. Pathol. 6, 275-297.

Ohashi, K., Parker, J. L., Ouchi, N., Higuchi, A., Vita, J. A., Gokce, N., Pedersen, A. A., Kalthoff, C., Tullin, S., Sams, A., Summer, R. and Walsh, K. (2010) Adiponectin promotes macrophage polarization toward an anti-inflammatory phenotype. J. Biol. Chem. 285 , 6153-6160.

Pajvani, U. B., Du, X., Combs, T. P., Berg, A. H., Rajala, M. W., Schulthess, T., Engel, J., Brownlee, M. and Scherer, P. E. (2003) Structure-function studies of the adipocyte-secreted hormone Acrp30/ adiponectin. Implications fpr metabolic regulation and bioactivity. J. Biol. Chem. 278, 9073-9085.

Pajvani, U. B., Hawkins, M., Combs, T. P., Rajala, M. W., Doebber, T., Berger, J. P., Wagner, J. A., Wu, M., Knopps, A., Xiang, A. H., Utzschneider, K. M., Kahn, S. E., Olefsky, J. M., Buchanan, T. A. and Scherer, P. E. (2004) Complex distribution, not absolute amount of adiponectin, correlates with thiazolidinedione-mediated improvement in insulin sensitivity. J. Biol. Chem. 279, 1215212162.

Papakonstantinou, E., Roth, M. and Karakiulakis, G. (2012) Hyaluronic acid: a key molecule in skin aging. Dermatoendocrinol. 4, 253-258.

Park, P. H., McMullen, M. R., Huang, H., Thakur, V. and Nagy, L. E. (2007) Short-term treatment of RAW264.7 macrophages with adiponectin increases tumor necrosis factor-alpha (TNF-alpha) expression via ERK1/2 activation and Egr-1 expression: role of TNF- alpha in adiponectin-stimulated interleukin-10 production. J. Biol. Chem. 282, 21695-21703.

Pittayapruek, P., Meephansan, J., Prapapan, O., Komine, M. and Ohtsuki, M. (2016) Role of matrix metalloproteinases in photoaging and photocarcinogenesis. Int. J. Mol. Sci. 17, 868.

Rossi, A. and Lord, J. M. (2013) Adiponectin inhibits neutrophil apoptosis via activation of AMP kinase, PKB and ERK 1/2 MAP kinase. Apoptosis 18, 1469-1480.

Rothenberg, M. E. and Hogan, S. P. (2006) The eosinophil. Annu. Rev. Immunol. 24, 147-174.

Scherer, P. E. (2006) Adipose tissue: from lipid storage compartment to endocrine organ. Diabetes 55, 1537-1545

Scherer, P. E., Williams, S., Fogliano, M., Baldini, G. and Lodish, H. F. (1995) A novel serum protein similar to C1q, produced exclusively in adipocytes. J. Biol. Chem. 270, 26746-26749.

Sereflican, B., Goksugur, N., Bugdayci, G., Polat, M. and Haydar Parlak, A. (2016) Serum visfatin, adiponectin, and tumor necrosis factor alpha (TNF- $\alpha$ ) levels in patients with psoriasis and their correlation with disease severity. Acta Dermatovenerol. Croat. 24, 13-19.

Shapiro, L. and Scherer, P. E. (1998) The crystal structure of a complement-1q family protein suggests an evolutionary link to tumor necrosis factor. Curr. Biol. 8, 335-338.

Shibata, S., Tada, Y., Asano, Y., Hau, C. S., Kato, T., Saeki, H., Yamauchi, T., Kubota, N., Kadowaki, T. and Sato, S. (2012) Adiponectin regulates cutaneous wound healing by promoting keratinocyte proliferation and migration via the ERK signaling pathway. J. Immunol. $189,3231-3241$

Shibata, S., Tada, Y., Hau, C. S., Mitsui, A., Kamata, M., Asano, Y., Sugaya, M., Kadono, T., Masamoto, Y., Kurokawa, M., Yamauchi, T., Kubota, N., Kadowaki, T. and Sato, S. (2015) Adiponectin regulates psoriasiform skin inflammation by suppressing IL-17 production from $\gamma \delta$-T cells. Nat. Commun. 6, 7687.

Sjerobabski-Masnec, I. and Šitum, M. (2010) Skin aging. Acta Clin. Croat. 49, 515-518.

Steffens, S. and Mach, F. (2008) Adiponectin and adaptive immunity: linking the bridge from obesity to atherogenesis. Circ. Res. 102, 140-142.

Stochmal, A., Czuwara, J., Zaremba, M. and Rudnicka, L. (2020) Altered serum level of metabolic and endothelial factors in patients with systemic sclerosis. Arch. Dermatol. Res. 312, 453-458.

Sun, Y. and Lodish, H. F. (2010) Adiponectin deficiency promotes tumor growth in mice by reducing macrophage infiltration. PLOS ONE 5, e11987.

Takahashi, H. and lizuka, H. (2012) Psoriasis and metabolic syndrome. J. Dermatol. 39, 212-218.

Takemura, Y., Ouchi, N., Shibata, R., Aprahamian, T., Kirber, M. T., Summer, R. S., Kihara, S. and Walsh, K. (2007) Adiponectin modulates inflammatory reactions via calreticulin receptor-dependent clearance of early apoptotic bodies. J. Clin. Invest. 117, 375-386.

Tobin, D. J. (2018) Early evidence for opposing effects of full versus fragmented adiponectin on melanogenesis in human epidermal melanocytes. Br. J. Dermatol. 179, 561-562.

Tsang, J. Y., Li, D., Ho, D., Peng, J., Xu, A., Lamb, J., Chen, Y. and Tam, P. K. (2011) Novel immunomodulatory effects of adiponectin on dendritic cell functions. Int. Immunopharmacol. 11, 604-609.

Tsatsanis, C., Zacharioudaki, V., Androulidaki, A., Dermitzaki, E., Charalampopoulos, I., Minas, V., Gravanis, A. and Margioris, A. N. (2005) Adiponectin induces TNF-alpha and IL-6 in macrophages and promotes tolerance to itself and other pro-inflammatory stimuli. Biochem. Biophys. Res. Commun. 335, 1254-1263.

Vitseva, O. I., Tanriverdi, K., Tchkonia, T. T., Kirkland, J. L., McDonnell, M. E., Apovian, C. M., Freedman, J. and Gokce, N. (2008) Inducible Toll-like receptor and NF-kB regulatory pathway expression in human adipose tissue. Obesity 16, 932-937.

Waki, H., Yamauchi, T., Kamon, J., Kita, S., Ito, Y., Hada, Y., Uchida, S., Tsuchida, A., Takekawa, S. and Kadowaki, T. (2005) Generation of globular fragment of adiponectin by leukocyte elastase secreted by monocytic cell line THP-1. Endocrinology 146, 790-796.

Wang, A. S. and Dreesen, O. (2018) Biomarkers of cellular senescence and skin aging. Front. Genet. 9, 247.

Wang, Z. V. and Scherer, P. E. (2016) Adiponectin, the past two decades. J. Mol. Cell Biol. 8, 93-100. 
Wensveen, F. M., Jelenčić, V., Valentić, S., Šestan, M., Wensveen, T. T., Theurich, S., Glasner, A., Mendrila, D., Štimac, D., Wunderlich, F. T., Brüning, J. C., Mandelboim, O. and Polić, B. (2015) NK cells link obesity-induced adipose stress to inflammation and insulin resistance. Nat. Immunol. 16, 376-385.

Wilk, S., Jenke, A., Stehr, J., Yang, C. A., Bauer, S., Göldner, K. Kotsch, K., Volk, H. D., Poller, W., Schultheiss, H. P., Skurk, C. and Scheibenbogen, C. (2013) Adiponectin modulates NK-cell function. Eur. J. Immunol. 43, 1024-1033.

Withers, S. B., Forman, R., Meza-Perez, S., Sorobetea, D., Sitnik, K., Hopwood, T., Lawrence, C. B., Agace, W. W., Else, K. J., Heagerty, A. M., Svensson-Frej, M. and Cruickshank, S. M. (2017) Eosinophils are key regulators of perivascular adipose tissue and vascular functionality. Sci. Rep. 7, 44571.

Wolf, A. M., Wolf, D., Rumpold, H., Enrich, B. and Tilg, H. (2004) Adiponectin induces the anti-inflammatory cytokines IL-10 and IL-1RA in human leukocytes. Biochem. Biophys. Res. Commun. 323, 630635.

Woodley, D. T. (2017) Distinct fibroblasts in the papillary and reticular dermis: implications for wound healing. Dermatol. Clin. 35, 95-100.

Wulster-Radcliffe, M. C., Ajuwon, K. M., Wang, J., Christian, J. A. and Spurlock, M. E. (2004) Adiponectin differentially regulates cytokines in porcine macrophages. Biochem. Biophys. Res. Commun. 316, 924-929.

Yamaguchi, N., Argueta, J. G., Masuhiro, Y., Kagishita, M., Nonaka, K., Saito, T., Hanazawa, S. and Yamashita, Y. (2005) Adiponectin inhibits Toll-like receptor family-induced signaling. FEBS Lett. 579, 6821-6826.

Yamamoto, R., Ueki, S., Moritoki, Y., Kobayashi, Y., Oyamada, H., Konno, Y., Tamaki, M., Itoga, M., Takeda, M., Ito, W. and Chihara, J. (2013) Adiponectin attenuates human eosinophil adhesion and chemotaxis: implications in allergic inflammation. J. Asthma 50, 828-835

Yamashita, T., Lakota, K., Taniguchi, T., Yoshizaki, A., Sato, S., Hong, W., Zhou, X., Sodin-Semrl, S., Fang, F., Asano, Y. and Varga, J. (2018) An orally-active adiponectin receptor agonist mitigates cutaneous fibrosis, inflammation and microvascular pathology in a murine model of systemic sclerosis. Sci. Rep. 8, 11843.

Yamauchi, T., Kamon, J., Ito, Y., Tsuchida, A., Yokomizo, T., Kita, S., Sugiyama, T., Miyagishi, M., Hara, K., Tsunoda, M., Murakami, K., Ohteki, T., Uchida, S., Takekawa, S., Waki, H., Tsuno, N. H., Shibata, Y., Terauchi, Y., Froguel, P., Tobe, K., Koyasu, S., Taira, K., Kitamura, T., Shimizu, T., Nagai, R. and Kadowaki, T. (2003) Cloning of adiponectin receptors that mediate antidiabetic metabolic effects. Nature 423, 762-769.

Yang, J., Lin, S. C., Chen, G., He, L., Hu, Z., Chan, L., Trial, J., Entman, M. L. and Wang, Y. (2013) Adiponectin promotes monocyteto-fibroblast transition in renal fibrosis. J. Am. Soc. Nephrol. 24, 1644-1659.

Yoo, J. A., Yu, E., Park, S. H., Oh, S. W., Kwon, K., Park, S. J., Kim, H., Yang, S., Park, J. Y., Cho, J. Y., Kim, Y. J. and Lee, J. (2020) Blue light irradiation induces human keratinocyte cell damage via transient receptor potential vanilloid 1 (TRPV1) regulation. Oxid. Med. Cell. Longev. 2020, 8871745.

Yuki, T., Yoshida, H., Akazawa, Y., Komiya, A., Sugiyama, Y. and Inoue, S. (2011) Activation of TLR2 enhances tight junction barrier in epidermal keratinocytes. J. Immunol. 187, 3230-3237.

Zeng, Q., Macri, L. K., Prasad, A., Clark, R. A. F., Zeugolis, D. I., Hanley, C., Garcia, Y., Pandit, A., Leavesley, D. I., Stupar, D., Fernandez, M. L., Fan, C. and Upton, Z. (2017) 6.20 Skin tissue engineering. In Comprehensive Biomaterials II (P. Ducheyne, Ed.), pp. 334-382. Elsevier, Oxford. 